\title{
2,2-Diphenyl-1-picrylhydrazyl (DPPH) radical scavenging activity of extracts from Aloiampelos striatula
}

\author{
${ }^{1}$ Mokoroane, K.T., ${ }^{1, *}$ Pillai, M.K. and ${ }^{2}$ Magama, S. \\ ${ }^{I}$ Department of Chemistry and Chemical Technology, Faculty of Science and Technology, National \\ University of Lesotho, Roma Campus, P.O. Roma 180, Kingdom of Lesotho, Southern Africa \\ ${ }^{2}$ Department of Biology, Faculty of Science and Technology, National University of Lesotho, Roma Campus, \\ P.O. Roma 180, Kingdom of Lesotho, Southern Africa
}

\begin{abstract}
Article history:
Received: 21 May 2020

Received in revised form: 25

June 2020

Accepted: 4 July 2020

Available Online: 23 August 2020

Keywords:

Aloiampelos striatula,

Asphodelaceae,

Antioxidant activity,

DPPH radical scavenging assay

DOI:

https://doi.org/10.26656/fr.2017.4(6).241
\end{abstract}

\begin{abstract}
Hexane, chloroform, acetone, methanolic and water extracts from leaves and stem-bark of Aloiampelos striatula were evaluated for their antioxidant activity by 2,2-diphenyl-1picrylhydrazyl (DPPH) radical scavenging assay. The hexane, chloroform, acetone, methanolic and water extracts from leaves of $A$. striatula showed scavenging activity ranging from $10.30 \pm 0.41-30.14 \pm 1.4,30.49 \pm 0.85-45.95 \pm 0.22,38.45 \pm 0.49-51.65 \pm 0.95$, $34.83 \pm 1.53-64.98 \pm 0.45$ and $54.37 \pm 1.24$ - $66.74 \pm 0.89 \%$, respectively, at various concentrations. The hexane, chloroform, acetone, methanolic and water extracts from stem -bark of A. striatula showed scavenging activity ranging from $12.53 \pm 3.07-29.81 \pm 2.43$, $17.80 \pm 5.17-37.20 \pm 2.13,6.15 \pm 0.24-62.79 \pm 3.82,38.23 \pm 1.18-67.32 \pm 0.55$ and $3.16 \pm 0.40$ - 70.66 $\pm 0.18 \%$, respectively, at various concentrations. Additionally, the $\mathrm{IC}_{50}$ values of these extracts were also determined and were found to be in the range of $<200$ to $>3000$ $\mu \mathrm{g} / \mathrm{mL}$. The positive control, vitamin $\mathrm{C}$, showed an $\mathrm{IC}_{50}$ value of $<200 \mu \mathrm{g} / \mathrm{mL}$. The therapeutic applications of $A$. striatula are often in traditional Basotho medicine in the Kingdom of Lesotho, which include treating skin problems, high blood pressure, sexually transmitted illnesses, common colds, blood cleansing, stomach ailments and dressing of wounds. Further studies on this plant are required to explore this plant for its commercial applications.
\end{abstract}

\section{Introduction}

Aloiampelos striatula belongs to the Asphodelaceae family of the genus Aloiampelos (Reynolds, 1950; Van Wyk and Smith, 1996; Seleteng-Kose et al., 2015). The vernacular names of this plant are mohalakane and seholobe (Seleteng-Kose et al., 2015). A. striatula is also known by other names such as Aloe striatula, hardy aloe and striped - stemmed aloe. A. striatula is distributed throughout the Kingdom of Lesotho and South Africa (Reynolds, 1950). The western region of the Kingdom of Lesotho and Eastern Cape and Free State provinces of South Africa are rich in A. striatula (Reynolds, 1950). A. striatula has a slender semi-woody stem, grows into a large shrub and reaches up to 2 - meter height. $A$. striatula produces reddish-orange or yellowish flowers (Smith and Van Wyk, 2008). A. striatula has dark green curved thin leaves, which are much alike aloe vera leaves. The therapeutic applications of A. striatula in the traditional Basotho medicine in the Kingdom of Lesotho (Seleteng-Kose et al., 2015) includes treating skin problems, high blood pressure, sexually transmitted illnesses, common colds, blood cleansing, stomach ailments and dressing of wounds (Van Wyk and Gericke, 2000; Moffett, 2010; Seleteng-Kose et al., 2015). Particularly, the leaves of $A$. striatula reported having most of the therapeutic potentials (Seleteng-Kose et al., 2015). The leaves are soaked in water and consumed by the Basotho for various ailments (Moteetee and Van Wyk, 2011; Moteetee et al., 2017). Our literature search showed that this plant has not been studied extensively both phytochemically and pharmacologically. To the best of our knowledge, the antioxidant activity of $A$. striatula has not been reported previously. Therefore, the aim of this study was to evaluate the antioxidant activity of hexane, chloroform acetone, methanolic and water extracts obtained from the leaves and stem-bark of $A$. striatula by DPPH radical scavenging assay. Additionally, the $\mathrm{IC}_{50}$ values of these extracts were also determined. This is the first report of this kind from this species gathered from the Kingdom of Lesotho. 


\section{Materials and methods}

\subsection{Plant materials}

The leaves and stem-bark of A. striatula were collected at Mafikeng village, Roma, Maseru district, The Kingdom of Lesotho, Southern Africa. The plant material was identified by Dr Lerato Seleteng-Kose. Voucher specimen for leaves (AALS) and stem-bark (AASB) were kept in the Organic Chemistry Research Laboratory, Department of Chemistry and Chemical Technology, Faculty of Science and Technology, The National University of Lesotho, Roma campus, The Kingdom of Lesotho.

\subsection{Preparation of plant extracts}

Approximately, $10 \mathrm{~kg}$ of leaves and $6 \mathrm{~kg}$ of stem-bark of $A$. striatula were collected, allowed to air - dry at room temperature separately for six weeks and then ground into fine powder using a laboratory blender (Waring Blender, Blender 80119, Model HGB2WT93, 240V AC, 3.5 AMPs, Laboratory and Analytical Supplies). For the current study, a mass of $90.65,101.55$, $203.11,85.65$ and $263.96 \mathrm{~g}$ of powdered leaves was taken separately in RB-flasks and was extracted as per the procedure given in the literature (Pillai et al., 2019; Matamane et al., 2020) with slight modification as detailed below. Approximately, 1 L of hexane, chloroform, acetone, methanol and water were added separately into each RB-flask. The mixtures were macerated for 2 weeks with occasional shaking. The resulting solutions were filtered off separately and the solvents were removed by simple distillation. A mass of $2.24,10.63,29.38$ and $26.32 \mathrm{~g}$ of hexane, chloroform, acetone and methanolic extracts, respectively, were obtained after removal of solvents. However, in the case of water extract, the solvent was removed as much as possible by vacuo and the resulting mass was left to stand for two weeks in a fume hood. A mass of $55.47 \mathrm{~g}$ of high viscous water extract was obtained and was used for further analysis. Using similar extraction procedures, $1.10,0.89,0.75,0.09$ and $2.10 \mathrm{~g}$ of hexane, chloroform, acetone, methanolic and water extracts were obtained, respectively from 99.98, 101.34, 104.22, 100.00 and $98.99 \mathrm{~g}$ of powdered stem-bark.

\subsection{Chemicals used}

Hexane, chloroform, methanol, acetone (all solvents were of AR grade, 99.5\%), ascorbic acid (AR grade), tris (hydroxymethyl)aminomethane (AR grade) and DPPH (AR grade) were all purchased from Sigma - Aldrich. Deionized water was available at Organic Chemistry Laboratory, NUL, Roma campus, Lesotho.
$2.4 \mathrm{DPPH}$ radical scavenging assay and determination of $I C_{50}$ values

DPPH radical scavenging assay was carried out using a method as described in the literature (Kim et al., 2002; Dontha, 2016; Pillai et al., 2019; Matamane et al., 2020). Briefly, a stock solution of methanolic extract was prepared at a concentration of $3.0 \mathrm{mg}$ of extract in $1 \mathrm{~mL}$ of $50 \%$ methanol $(\mathrm{v} / \mathrm{v})$. Serial dilutions were made from this stock solution to obtain solutions with concentrations of $3000,2000,1500,1000,800,500$ and $200 \mu \mathrm{g} / \mathrm{mL}$. Solutions without extract concentration served as a negative control (Pillai et al., 2019). A solution of $3.94 \mathrm{mg}$ of DPPH in $100 \mathrm{~mL}$ of methanol served as oxidant, which was prepared just before use and stored in dark to minimize degradation (Pillai et al., 2019). A volume of $0.1 \mathrm{~mL}$ sample of plant extract solution was mixed with $1.0 \mathrm{~mL}$ of $0.1 \mathrm{mM} \mathrm{DPPH}$ solution and $0.45 \mathrm{~mL}$ of $50 \mathrm{mM}$ Tris - HCL buffer $(\mathrm{pH}=$ 7.40) (Pillai et al., 2019). Similarly, stock solutions of hexane, chloroform, acetone and water extracts were prepared at a concentration of $3.0 \mathrm{mg}$ of extract in $1 \mathrm{~mL}$ of $50 \%$ methanol $(\mathrm{v} / \mathrm{v})$. Further dilutions were made from these stock solutions to obtain solutions with concentrations of 3000, 2000, 1500, 1000, 800, 500 and $200 \mu \mathrm{g} / \mathrm{mL}$ (Pillai et al., 2019). A volume of $0.1 \mathrm{~mL}$ each of this extract was mixed separately with $1.0 \mathrm{~mL}$ of $0.1 \mathrm{mM}$ DPPH solution and $0.45 \mathrm{~mL}$ of $50 \mathrm{mM}$ Tris HCL buffer $(\mathrm{pH}=7.40)$. A stock solution of vitamin $\mathrm{C}$ $(0.3 \mathrm{~g})$ in $50 \%$ methanol $(\mathrm{v} / \mathrm{v})$ was prepared and serial dilutions were made as previously, which served as a positive control. A volume of $0.1 \mathrm{~mL}$ of this solution was mixed with $1.0 \mathrm{~mL}$ of $0.1 \mathrm{mM}$ DPPH solution and $0.45 \mathrm{~mL}$ of $50 \mathrm{mM}$ Tris - HCL buffer $(\mathrm{pH}=7.40)$. The mixtures were incubated for $30 \mathrm{~min}$ and the absorbance (optical density) of the mixture was measured at $517 \mathrm{~nm}$ using an MRC spectrophotometer (Mode Spectro UV $11 \mathrm{~S} / \mathrm{N}$ : UEB 1704020). The following equation was used to calculate the percentage of DPPH radical scavenging activity of extracts.

$$
\text { DPPH Scavenged }(\%)=\left[\left(\mathrm{A}_{\text {cont }}-\mathrm{A}_{\text {test }}\right) / \mathrm{A}_{\text {cont }}\right] \times 100
$$

Where $A_{\text {test }}=$ Absorbance in the presence of extract or positive control and $\mathrm{A}_{\text {cont }}=$ Absorbance of negative control (i.e. without extract).

The $\mathrm{IC}_{50}$ value is defined as the concentration of extract that inhibits the formation of DPPH radical by 50\% (Moyo et al., 2013; Ndhlala et al., 2013). A lower value of $\mathrm{IC}_{50}$ represents higher antioxidant activity and vice versa. The $\mathrm{IC}_{50}$ values were calculated using Microsoft Excel by plotting extract concentration versus percentage inhibition of DPPH radical. Each experiment was carried out in triplicate and the average of the three values was used to calculate $\mathrm{IC}_{50}$ value for each extract. 
Standard deviation was calculated for each concentration from the three values of the experiment.

\subsection{Statistical analysis}

The statistical data analysis was performed using SPSS Data Editor v16.0 statistics program. The differences were considered statistically significant when $\mathrm{p} \leq 0.05$.

\section{Results and discussion}

Table 1 summarizes the percentage inhibition of DPPH radical scavenging activity of various extracts from leaves and stem-bark of A. striatula. A total of ten extracts were prepared. These are i). A. striatula-hexane extract from leaves (E1), ii). A. striatula-chloroform extract from leaves (E2), iii). A. striatula-acetone extract from leaves (E3), iv). A. striatula-methanolic extract from leaves (E4), v). A. striatula-water extract from leaves (E5), vi). A. striatula-hexane extract from stembark (E6), vii). A. striatula-chloroform extract from stem -bark (E7), viii). A. striatula-acetone extract from stembark (E8), ix). A. striatula-methanolic extract from stembark (E9) and x). A. striatula-water extract from stembark (E10). The extract E1 showed 10.30 \pm 0.41 , $11.90 \pm 2.74, \quad 14.39 \pm 0.62, \quad 16.37 \pm 1.57, \quad 19.60 \pm 2.58$, $24.19 \pm 6.80$ and $30.14 \pm 1.40 \%$ of inhibition at concentrations 200, 500,800,1000, 1500, 2000 and $3000 \mu \mathrm{g} / \mathrm{mL}$, respectively. The positive control, vitamin $\mathrm{C}$ showed $59.86 \pm 10.25, \quad 64.16 \pm 0.08, \quad 66.12 \pm 0.92$, $68.14 \pm 0.69,69.31 \pm 0.40,69.56 \pm 0.01$ and $72.22 \pm 0.78 \%$ of inhibition at concentrations 200, 500, 800, 1000, 1500,2000 and $3000 \mu \mathrm{g} / \mathrm{mL}$, respectively. Compared to the positive control, E1 showed much lower radical scavenging activity at all concentrations. The extract E2 exhibited $\quad 30.49 \pm 0.85, \quad 32.28 \pm 0.05, \quad 34.59 \pm 0.74$, $37.43 \pm 1.90,40.79 \pm 3.57,43.94 \pm 1.82$ and $45.95 \pm 0.22 \%$ of inhibition at concentrations 200, 500, 800, 1000,
1500, 2000 and $3000 \mu \mathrm{g} / \mathrm{mL}$, respectively. Compared to the positive control, E2 showed lower radical scavenging activity at all concentrations. The extract E3 showed $38.45 \pm 0.49, \quad 40.84 \pm 0.82, \quad 42.89 \pm 0.29, \quad 44.60 \pm 1.38$, $47.10 \pm 1.58,49.26 \pm 1.21$ and $51.65 \pm 0.95 \%$ of inhibition at concentrations 200, 500, 800,1000, 1500, 2000 and $3000 \mu \mathrm{g} / \mathrm{mL}$, respectively. Compared to the positive control, E3 also showed lower radical scavenging activity at all concentrations. However, E3 showed relatively higher scavenging activity than E1 and E2 at all concentrations. The extract E4 exhibited $34.83 \pm 1.53$, $38.12 \pm 0.43, \quad 42.82 \pm 0.51, \quad 47.04 \pm 2.03, \quad 52.77 \pm 2.04$, $58.30 \pm 1.17$ and $64.98 \pm 0.45 \%$ of inhibition at concentrations 200, 500,800,1000, 1500, 2000 and $3000 \mu \mathrm{g} / \mathrm{mL}$, respectively. Compared to the positive control, E4 also showed lower radical scavenging activity at all concentrations. However, E4 showed comparable scavenging activity as that of E3 at all concentrations. The extract E5 showed 54.37 \pm 1.24 , $56.44 \pm 0.11, \quad 59.25 \pm 0.63, \quad 61.22 \pm 0.61, \quad 61.85 \pm 0.18$, $64.45 \pm 0.59$ and $66.74 \pm 0.89 \%$ of inhibition at concentrations 200, 500,800,1000, 1500, 2000 and $3000 \mu \mathrm{g} / \mathrm{mL}$, respectively. Compared to the positive control, E5 showed slightly lower radical scavenging activity at all concentrations. However, E5 showed higher scavenging activity than E4 at all concentrations and showed the highest scavenging activity and most potent among the extracts from the leaves of A. striatula (Table 1).

The extract E6 exhibited 12.53 $\pm 3.07,15.74 \pm 1.85$, $17.88 \pm 2.79, \quad 19.57 \pm 1.19,21.09 \pm 2.17,23.85 \pm 1.41$ and $29.81 \pm 2.43 \%$ of inhibition at concentrations 200, 500, $800,1000,1500,2000$ and $3000 \mu \mathrm{g} / \mathrm{mL}$, respectively. This result revealed that E6 showed much lower radical scavenging activity than the positive control, at all concentrations. The extract E7 exhibited $17.80 \pm 5.17$, $18.82 \pm 0.54, \quad 23.41 \pm 3.09, \quad 26.58 \pm 0.03, \quad 30.74 \pm 0.82$,

Table 1. The percentage inhibition of DPPH radical by various extracts from leaves and stem-bark of $A$. striatula

\begin{tabular}{cccccccc}
\hline \multirow{2}{*}{ Extracts } & \multicolumn{7}{c}{ Concentrations $(\mu \mathrm{g} / \mathrm{mL}) /$ Inhibition $(\%)$} \\
\cline { 2 - 8 } & 200 & 500 & 800 & 1000 & 1500 & 2000 & 3000 \\
\hline E1 & $10.30 \pm 0.41^{\mathrm{a}}$ & $11.90 \pm 2.74^{\mathrm{b}}$ & $14.39 \pm 0.62^{\mathrm{a}}$ & $16.37 \pm 1.57^{\mathrm{a}}$ & $19.60 \pm 2.58^{\mathrm{b}}$ & $24.19 \pm 6.80^{\mathrm{c}}$ & $30.14 \pm 1.40^{\mathrm{a}}$ \\
E2 & $30.49 \pm 0.85^{\mathrm{a}}$ & $32.28 \pm 0.05^{\mathrm{a}}$ & $34.59 \pm 0.74^{\mathrm{a}}$ & $37.43 \pm 1.90^{\mathrm{a}}$ & $40.79 \pm 3.57^{\mathrm{b}}$ & $43.94 \pm 1.82^{\mathrm{a}}$ & $45.95 \pm 0.22^{\mathrm{a}}$ \\
E3 & $38.45 \pm 0.49^{\mathrm{a}}$ & $40.84 \pm 0.82^{\mathrm{a}}$ & $42.89 \pm 0.29^{\mathrm{a}}$ & $44.60 \pm 1.38^{\mathrm{a}}$ & $47.10 \pm 1.58^{\mathrm{a}}$ & $49.26 \pm 1.21^{\mathrm{a}}$ & $51.65 \pm 0.95^{\mathrm{a}}$ \\
E4 & $34.83 \pm 1.53^{\mathrm{a}}$ & $38.12 \pm 0.43^{\mathrm{a}}$ & $42.82 \pm 0.51^{\mathrm{a}}$ & $47.04 \pm 2.03^{\mathrm{a}}$ & $52.77 \pm 2.04^{\mathrm{a}}$ & $58.30 \pm 1.17^{\mathrm{a}}$ & $64.98 \pm 0.45^{\mathrm{a}}$ \\
E5 & $54.37 \pm 1.24^{\mathrm{a}}$ & $56.44 \pm 0.11^{\mathrm{a}}$ & $59.25 \pm 0.63^{\mathrm{a}}$ & $61.22 \pm 0.61^{\mathrm{a}}$ & $61.85 \pm 0.18^{\mathrm{a}}$ & $64.45 \pm 0.59^{\mathrm{a}}$ & $66.74 \pm 0.89^{\mathrm{a}}$ \\
E6 & $12.53 \pm 3.07^{\mathrm{b}}$ & $15.74 \pm 1.85^{\mathrm{a}}$ & $17.88 \pm 2.79^{\mathrm{b}}$ & $19.57 \pm 1.19^{\mathrm{a}}$ & $21.09 \pm 2.17^{\mathrm{a}}$ & $23.85 \pm 1.41^{\mathrm{a}}$ & $29.81 \pm 2.43^{\mathrm{a}}$ \\
E7 & $17.80 \pm 5.17^{\mathrm{c}}$ & $18.82 \pm 0.54^{\mathrm{a}}$ & $23.41 \pm 3.09 \mathrm{a}$ & $26.58 \pm 0.03^{\mathrm{a}}$ & $30.74 \pm 0.82^{\mathrm{a}}$ & $34.91 \pm 0.00$ & $37.20 \pm 2.13^{\mathrm{a}}$ \\
E8 & $6.15 \pm 0.24^{\mathrm{a}}$ & $13.17 \pm 1.82^{\mathrm{a}}$ & $27.66 \pm 0.41^{\mathrm{a}}$ & $33.37 \pm 0.08^{\mathrm{a}}$ & $35.67 \pm 0.29^{\mathrm{a}}$ & $48.62 \pm 2.09^{\mathrm{a}}$ & $62.79 \pm 3.82^{\mathrm{b}}$ \\
E9 & $38.23 \pm 1.18^{\mathrm{a}}$ & $41.20 \pm 0.21^{\mathrm{a}}$ & $42.28 \pm 1.14^{\mathrm{a}}$ & $46.05 \pm 0.10^{\mathrm{a}}$ & $48.65 \pm 0.71^{\mathrm{a}}$ & $51.08 \pm 0.38^{\mathrm{a}}$ & $67.32 \pm 0.55^{\mathrm{a}}$ \\
E10 & $3.16 \pm 0.40^{\mathrm{a}}$ & $14.34 \pm 2.61^{\mathrm{b}}$ & $18.36 \pm 1.54^{\mathrm{a}}$ & $52.22 \pm 1.27^{\mathrm{a}}$ & $59.11 \pm 1.06^{\mathrm{a}}$ & $65.13 \pm 2.03^{\mathrm{a}}$ & $70.66 \pm 0.18^{\mathrm{a}}$ \\
Vitamin C & $59.86 \pm 10.25^{\mathrm{e}}$ & $64.16 \pm 0.08^{\mathrm{a}}$ & $66.12 \pm 0.92^{\mathrm{a}}$ & $68.14 \pm 0.69^{\mathrm{a}}$ & $69.31 \pm 0.40^{\mathrm{a}}$ & $69.56 \pm 0.01^{\mathrm{a}}$ & $72.22 \pm 0.78^{\mathrm{a}}$ \\
\hline
\end{tabular}

Values with different superscript letters are significantly different. 
$34.91 \pm 0.00$ and $37.20 \pm 2.13 \%$ of inhibition at concentrations 200, 500,800, 1000, 1500, 2000 and $3000 \mu \mathrm{g} / \mathrm{mL}$, respectively. Therefore, E7 showed lower scavenging activity than the positive control. The extract E8 exhibited $6.15 \pm 0.24, \quad 13.17 \pm 1.82, \quad 27.66 \pm 0.41$, $33.37 \pm 0.08,35.67 \pm 0.29,48.62 \pm 2.09$ and $62.79 \pm 3.82 \%$ of inhibition at concentrations 200, 500, 800, 1000, 1500,2000 and $3000 \mu \mathrm{g} / \mathrm{mL}$, respectively. This result indicated that at lower concentrations, E8 showed much lower scavenging activity compared to the positive control. However, at higher concentrations, the scavenging activity of E8 was very significant. It means that at higher concentrations, E8 might have rich phytochemicals such as polyphenols, phenolic acids, flavonoids etc. in sufficient quantities. These phytochemicals have been reported as important classes of antioxidants in natural sources (Array et al., 2019; Rodrigues et al., 2019). The extract E9 exhibited $38.23 \pm 1.18, \quad 41.20 \pm 0.21, \quad 42.28 \pm 1.14, \quad 46.05 \pm 0.10$, $48.65 \pm 0.71,51.08 \pm 0.38$ and $67.32 \pm 0.55 \%$ of inhibition at concentrations 200, 500,800,1000, 1500, 2000 and $3000 \mu \mathrm{g} / \mathrm{mL}$, respectively. The extract E9 showed lower scavenging activity at all concentrations relative to the positive control. However, E9 showed significant scavenging activity at each concentration and much higher scavenging activity than E8. The extract E10 showed $3.16 \pm 0.40,14.34 \pm 2.61,18.36 \pm 1.54,52.22 \pm 1.27$, $59.11 \pm 1.06,65.13 \pm 2.03$ and $70.66 \pm 0.18 \%$ of inhibition at concentrations $200,500,800,1000,1500,2000$ and $3000 \mu \mathrm{g} / \mathrm{mL}$, respectively. This result indicated that at lower concentrations, E10 showed much lower scavenging activity than the positive control. However, at higher concentrations at 1000, 1500, 2000 and 3000 $\mu \mathrm{g} / \mathrm{mL}$, it showed significant scavenging activity and showed comparable scavenging activity as that of positive control (Table 1). Again, at higher concentrations, E10 might have contained scavenging rich phytochemicals such as polyphenols, phenolic acids, flavonoids etc. in sufficient quantities.

Additionally, the $\mathrm{IC}_{50}$ values of these ten extracts were also determined and the results are summarized in Table 2. Extracts E1 - E10 showed $\mathrm{IC}_{50}$ values of $>3000$, $\sim 2300, \sim 1400, \sim 1200,<200,>3000,>3000, \sim 2200$, $\sim 1660$ and $>3000 \mu \mathrm{g} / \mathrm{mL}$, respectively (Table 2). The positive control, vitamin $\mathrm{C}$, showed an $\mathrm{IC}_{50}$ value of $<200 \mu \mathrm{g} / \mathrm{mL}$ (Table 2). The extract E5 was found to be most potent with an $\mathrm{IC}_{50}$ value of $<200 \mu \mathrm{g} / \mathrm{mL}$ and this value was similar to the positive control.

The water extract from leaves of $A$. striatula (E5) was the most potent among all ten extracts. The extracts E2, E3, E4 and E9 showed significant scavenging activity at all concentrations. The extracts E8 and E10 showed lower scavenging activity at lower concentrations but at higher concentrations, both they exhibited significant activities. As stated previously, at higher concentrations, E8 and E10 might have contained scavenging rich phytochemicals such as polyphenols, phenolics, flavonoids etc. in sufficient quantities. The extracts E1, E6 and E7 showed weak to moderate scavenging activity at all concentrations and showed relatively lower scavenging activity among all ten extracts. The leaves of $A$. striatula reported having many therapeutic applications (Van Wyk and Gericke, 2000; Moffett, 2010; Seleteng-Kose et al., 2015). However, the therapeutic applications of stem-bark and root of $A$. striatula have not been reported, previously. This study also confirmed that the extracts from the leaves of $A$. striatula showed higher scavenging activity than the extracts from stem-bark. Particularly, the water extract from leaves of $A$. striatula (E5) showed the highest scavenging activity among all ten extracts and identified as the potent extract.

Table 2. $\mathrm{IC}_{50}$ values for various extracts from leaves and stem -bark of $A$. striatula

\begin{tabular}{ccc}
\hline S. No & Extracts & IC $_{50}$ in $\mu \mathrm{g} / \mathrm{mL}$ \\
\hline 1 & E1 & $>3000$ \\
2 & E2 & $\sim 2300$ \\
2 & E3 & $\sim 1400$ \\
4 & E4 & $\sim 1200$ \\
5 & E5 & $<200$ \\
6 & E6 & $>3000$ \\
7 & F7 & $>3000$ \\
8 & E8 & $\sim 2200$ \\
9 & E9 & $\sim 1660$ \\
10 & E10 & $>3000$ \\
11 & Vitamin C & $<200$ \\
\hline
\end{tabular}

\section{Conclusion}

In this study, hexane, chloroform, acetone, methanolic and water extracts from leaves and stem-bark of A. striatula were evaluated for their antioxidant activity by DPPH radical scavenging assay. Their radical scavenging activity at various concentrations was found to be in the range of $6.15 \pm 0.24$ to $70.66 \pm 0.18 \%$. Additionally, the $\mathrm{IC}_{50}$ values of these extracts were also determined and were found to be in the range of $<200$ to $>3000 \mu \mathrm{g} / \mathrm{mL}$. The positive control, vitamin $\mathrm{C}$, showed an $\mathrm{IC}_{50}$ value of $<200 \mu \mathrm{g} / \mathrm{mL}$. The water extract from leaves of $A$. striatula showed similar $\mathrm{IC}_{50}$ value as that of positive control. i.e. $<200 \mu \mathrm{g} / \mathrm{mL}$. This water extract from leaves of $A$. striatula finds therapeutic applications in the traditional Basotho medicine in the Kingdom of Lesotho. Our study also confirmed this fact that the water extract from leaves of $A$. striatula showed the highest scavenging potential and identified as the most potent among all ten extracts. This is the first report of this kind from this species collected from the Kingdom 
of Lesotho. Further studies on this plant will be useful to explore for any commercial applications.

\section{Conflict of interests}

The authors declare no conflict of interest.

\section{Acknowledgement}

The authors would like to thank the National University of Lesotho for support. The authors also thank Dr Lerato Seleteng-Kose for the identification of the plant material and Mrs Poloko Chubby Mokobocho for her support.

\section{References}

Array, E.J., Tonfack, D.F., Kingne, K.F., Kinge, E.E. and Womeni, H.M (2019). Effect of different extraction solvents on the phenolic content and antioxidant activity of turmeric (Curcuma longa) from South-West Region, Cameroon. Food Research, 3(1), 86 - 90. https://doi.org/10.26656/ fr.2017.3(1).227

Dontha, S. (2016). A review on antioxidants methods. Asian Journal of Pharmaceutical and Clinical Research, 9(Suppl. 2), $14 \quad$ - 32. https:// doi.org/10.22159/ajpcr.2016.v9s2.13092

Kim, J.K., Noh, J.H., Lee, S., Choi, J.S., Suh, H., Chung, H.Y., Song, Y.O. and Choi, W.C. (2002). The first total synthesis of 2,3,6-tribromo-4,5-dihydroxy benzoyl methyl ether (TDB) and its antioxidant activity. Bulletin of Korean Chemical Society, 23(5), 661 - 662. https://doi.org/10.512/bkcs.2002.23.5.661.

Matamane, R.P., Pillai, M.K. and Magama, S. (2020). DPPH radical scavenging activity of extracts from Urtica urens (Urticaceae). Journal of Medicinal Plants Research, 14(5), 232 - 238. https:// doi.org/10.5897/JMPR2019.6880

Moffett, R. (2010). Sesotho plant and animal names and plants used by the Basotho. Bloemfontein, South Africa: Sun Press. https:// doi.org/10.18820/9781920383206

Moteetee, A. and Seleteng-Kose, L. (2017). A review of medicinal plants used by Basotho for treatment of skin disorders: their phytochemical, antimicrobial and anti-inflammatory potential. African Journal of Traditional, Complementary Alternative Medicine, 14(5), 121 - $137 . \quad$ https://doi.org/10.21010/ ajtcam.v14i5.16.

Moteetee, A. and Van Wyk, B.E. (2011). The medical ethnobotany of Lesotho: A review. Bothalia, 41(1), 209 - 228. https://doi.org/10.4102/abc.v41i1.52

Moyo, M., Amoo, S.O., Ncube, B.M., Ndhlala, A.R.,
Finnie, J.F. and Van Staden, J. (2013). Phytochemical and antioxidant properties of unconventional leafy vegetables consumed in southern Africa. South African Journal of Botany, $84, \quad 65-71 . \quad$ https://doi.org/10.1016/ j.sajb.2012.09.010

Ndhlala, A.R., Aderogba, M.A., Ncube, B. and Van Staden, J. (2013). Antioxidative and cholinesterase inhibitory effects of leaf extracts and their isolated compounds from two closely related croton species. Molecules, 18(2), 1916 - $1932 . \quad \mathrm{https} / /$ doi.org/10.3390/molecules 18021916

Pillai, M.K., Lehlohonolo Isaac Santi, L.S. and Magama, S. (2019). DPPH radical scavenging activity of extracts from Rhamnus prinoides. Journal of Medicinal Plants Research, 13(15), 329 - https:// doi.org/10.5897/JMPR2019.6793

Rodrigues, R.F.C., Lima, A., Melo, A.C.F.L. and Trindade, R.A. (2019). Physicochemical characterisation, bioactive compounds and in vitro antioxidant activities of commercial integral grape juices. International Food Research Journal, 26(2), 469 - 479.

Seleteng-Kose, L., Moteetee, A. and Vuuren, V.S. (2015) Ethnobotanical survey of medicinal plants used in the Maseru district of Lesotho. Journal of Ethnopharmacology, 170, 184 - 200. https:// doi.org/10.1016/j.jep.2015.04.047

Smith, G.F. and Van Wyk, B.E. (2008). Aloes in Southern Africa. Cape Town, South Africa: Struik Publishers.

Reynolds, G.W. (1950). The aloes of Southern Africa. Cape Town, South Africa: Balkema Publishers.

Van Wyk, B.E. and Gericke, N. (2000). People's Plants: A guide to useful plants of Southern Africa. Pretoria, South Africa: Briza Publications.

Van Wyk, B.E. and Smith, G.F. (1996). Guide to the Aloes of Southern Africa. Pretoria, South Africa: Briza Publications. 